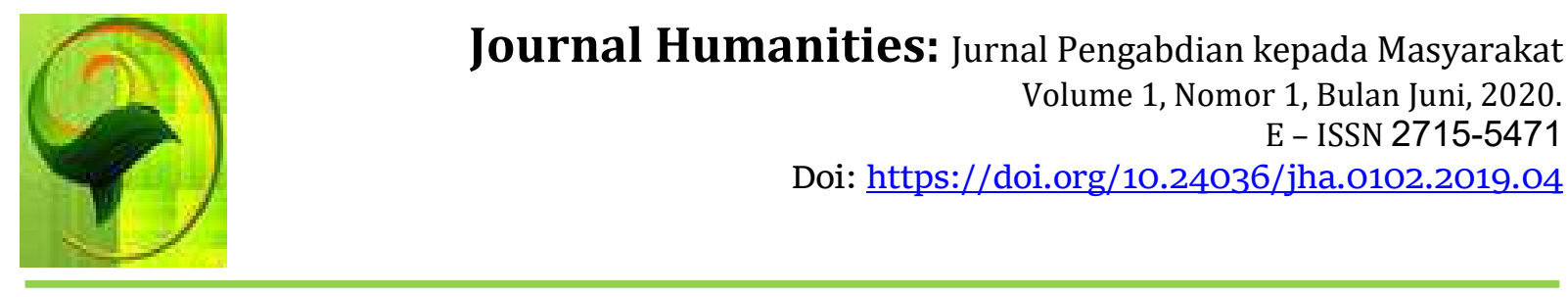

\title{
Dissemination and Training of Identification and Development of Sport Talent for Physical Education Teachers and Sports Trainers in the Province of West Sumatra
}

\author{
${ }^{1}$ Atradinal, ${ }^{2}$ Risky Syahputra, ${ }^{3}$ Oktarifaldi, ${ }^{4}$ Romi Mardela, ${ }^{5}$ Lucy Ptratama Putri, ${ }^{6}$ Irfan \\ Oktavianus, ${ }^{7}$ Sari Mariati ${ }^{9}$ Zainul Johor, ${ }^{9}$ Syahrial Bakhtiar \\ ${ }^{12345678910}$ Fakultas Ilmu Keolahragaan, Universitas Negeri Padang, Indonesia

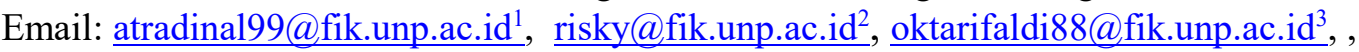 \\ romimardela@gmail.com ${ }^{4}$, lucy.prtama@fik.unp.ac.id ${ }^{5}$, Irfanadhe@fik.unp.ac.id \\ sarimariati@,fik.unp.ac.id ${ }^{7}, \underline{\text { zainul1959@,fik.unp.ac.id }}{ }^{8}, \underline{\text { syahrial@,fik.unp.ac.id }}$
}

\begin{abstract}
In many sporting events that have been held both nationally and internationally, Indonesia is still ranked below. Observations that have been made on PJOK teachers and trainers have found that they have not been able to identify and develop sports talent optimally by applying science. Research that has been done proves that an athlete is not only born but is also created through an appropriate talent identification program. There are at least two instruments that can be used to identify children's talents, namely I do and I Like. This application I like is online and saves and processes the data of children that we input and then will provide an output in the form of a dominant sport that is suitable for children. While I do in the form of tests of the ability of children with predetermined instruments. This service activity aims to: a) have skills in identifying and developing talent, b) understand and be skilled in using I do and I like instruments as part of talent identification, c) able to implement the management of talent identification instruments in their respective places. The method used uses the principle that every innovation received by PJOK teachers and trainers through PIE (Preparation, Implementation and Evaluation). This means that the delivery of innovations to Partners is taken through the stages of explanation, discussion, practice and evaluation stages are carried out with assistance in the learning and training process.
\end{abstract}

Keywords: talent identification, I like, I do

Abstrak
Pada banyak even olahraga yang telah diselenggrakan baik yang berskala Nasional maupun Internasional, Indonesia masih menduduki peringkat bawah. Observasi yang telah dilakukan terhadap guru PJOK dan pelatih ditemukan bahwa mereka belum mampu melakukan identifikasi dan pengambangan bakat olahraga secara maksimal dengan menerapkan ilmu pengetahuan. Penelitian yang telah dilakukan membuktikan bahwa seorang atlet tidak hanya dilahirkan namun juga diciptakan melalui program identifikasi bakat yang tepat. Setidaknya ada dua isntrumen yang dapat digunakan untuk megidentifikasi bakat anak, yaitu I do dan I Like. Aplikasi ini I like bersifat online dan menyimpan serta mengolah data anak yang kita input kemudian akan memberikan output berupa cabang olahraga dominan yang cocok dengan anak. Sedangkan I do berupa tes kemampuan anak dengan instrument yang telah ditetapkan. Kegiatan pengabdian ini bertujuan untuk: a) memiliki keterampilan dalam identifikasi dan pengembangan bakat, b) paham dan terampil dalam menggunakan instrument I do dan I like sebagai bagian dari identifikasi bakat, c) mampu mengimplementasiakan tatalaksana instrument identifikasi bakat ditempat masing-masing. Metode yang dilakukan menggunakan prinsip bahwa setiap inovasi yang diterima oleh guru PJOK dan pelatih melalui PIE (Preparation, Implementation and Evaluation). Hal ini berarti penyampaian inovasi kepada Mitra ditempuh melalui tahapan penjelasan, diskusi, praktek serta dilakukan tahapan evaluasi dengan pendampingan dalam proses pembelajaran dan pelatihan.

Keywords: identifikasi bakat, I do, I like 
Dissemination and Training of Identification and Development of Sport Talent for Physical

Education Teachers and Sports Trainers in the Province of West Sumatra

${ }^{1}$ Atradinal, ${ }^{2}$ Risky Syahputra, ${ }^{3}$ Oktarifaldi, ${ }^{4}$ Romi Mardela, ${ }^{5}$ Lucy Ptratama Putri, ${ }^{6}$ Irfan Oktavianus, ${ }^{7}$ Sari Mariati ${ }^{9}$ Zainul Johor,

${ }^{9}$ Syahrial Bakhtiar

\section{ANALISIS SITUASI}

Semua cabang olahraga yang ada didunia, baik cabang olahraga individu, olahraga kelompok, olahraga yang terkenla maupun yang tidak terkenal memiliki tujuan yang sama, yaitu menciptakan atlet dengan kemampuan terbaik demi mencapai prestasi yang maksimal. Namun, untuk mewujudkan tujuan tersebut tidaklah mudah. Hal inilah yang menjadi masalah utama bagi setiap ilmuan yang ada disetiap belahan dunia. Semua ingin menjadi nomor satu disetiap cabang olahraga, namun tidak setiap dari kita memiliki ilmu yang cukup untuk menciptakan atlet-atlet dengan prestasi yang gemilang. Belum adanya sistem identifikasi bakat untuk cabang, jenis dan nomor pertandingan olahraga yang paling cocok yang akan mereka ikuti, Identifikasi dan pengembangan bakat menjadi masalah utama bagi ilmuan olahraga, pelatih, bahkan orang tua, untuk mencapai kesuksesan sampai pada level pertandingan international (Carlos E.B. Gonçalves, Luís M.L. Rama, and António B. Figueiredo, 2012).

Banyak Negara yang telah melakukan investasi, riset dan pengembangan dalam bidang pencarian bakat demi mendapatkan talenta-talenta terbaik, salah satunya adalah Belanda. Investasi yang dilakukan bertujuan untuk meningkatkan persiapan sedini mungkin terhadap pelaksanaan eveneven olahraga besar seperti Olympiade. Karena seorang atlet tidak hanya dilahirkan melainkan juga diciptakan melalui proses yang cukup panjang. Deteksi, identifikasi dan pengembangan bakat dalam olahraga merupakan tantangan setiap badan atau organisasi olahraga (Pion, 2015). Dengan demikian sudah sepantasnya penggiat dan pengembang olahraga memikirkan bagaimana cara agar menciptakan atlet-atlet yang berbakat dan berprestasi sesuai cabang olahraga yang digelutinya.

Memberikan stimulus terhadap kemampuan gerak dasarnya, melakukan identifikasi dan pengembangan bakat merupakan proses panjang yang harus dilakui agar anak berada pada cabang olahraga yang benar. Oleh sebab itu, ketika bicara mengenai identifikasi bakat anak pada cabang olahraga mau tidak mau kita juga harus memahami pertumbuhan dan perkembangan fisik dan motorik anak. Merujuk pada teori pertumbuhan dan perkembangan fisik oleh Dynamic System Theory in Motor Development (Smith \& Thelen, 2003) menjelaskan bahwa perkembangan yang terjadi pada suatu individu seyogyanya bersifat non-linear, dan proses kontinu diselingi berhenti pada tahap tertentu. Sistem: organisme disusun oleh berbagai subsistem yang diatur sendiri.

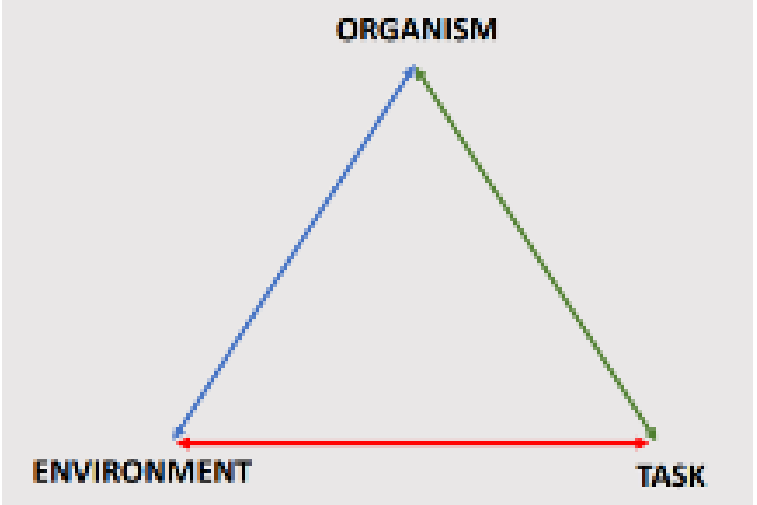

Gambar 1. Piramida pertumbuhan dan perkembangan gerak

Tahap pertumbuhan dan perkembangan gerak digambarkan seperti piramida diatas. Seorang individu yang terlatih dalam melakukan berbagai tugas gerak, sebenarnya mereka tidak begitu saja secara alami dapat bergerak dengan luwes. Namun setiap gerakan yang dapat mereka selesaikan dipengaruhi oleh lingkungan, garis keturunan dan seberapa banyak tugas gerak atau latihan-latihan yang diberikan kepada mereka. Kemampuan mendasar dalam melakukan gerak ini dikenal dengan istilah fundamental motor skill atau kemampuan gerak dasar (Arie Asnaldi et al., 2020). Pada dasarnya setiap anak harus dilatih agar memiliki kemampuan gerak dasar yang baik. Karena kemampuan gerak dasar ini merupakan fondasi awal dari kemampuan gerak kompleks (Payne dan Isaacs 2011) dan menjadi dasar dalam rangkaian gerak atau ABC gerak (Goodway and Robinson 2006; Hands 2012).

Keterampilan Gerak Dasar (KGD) adalah dasar untuk keterampilan gerak lanjutan dalam olahraga dan kegiatan fisik. Jika anak-anak tidak memiliki kompetensi dasar dalam KGD mereka tidak 


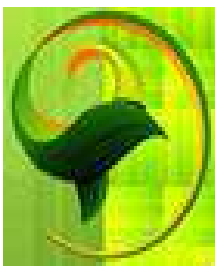

Journal Humanities: Jurnal Pengabdian kepada Masyarakat

Volume 1, Nomor 1, Bulan Juni, 2020.

E - ISSN 2715-5471

Doi: https://doi.org/10.24036/jha.0102.2019.04

akan mampu menerapkan keterampilan ini dalam olahraga \& permainan di masa kanak-kanak \& remaja, mereka tidak akan aktif berolahraga. Beberapa penelitian membenarkan hal ini, dijelaskan oleh salah seorang pakar (Pang \& Fong, 2009) bahwa agar mendapatkan kualitas gerak pada level tertinggi, seorang anak harus dilatih semenjak dini secara berkesinambungan karena kemampuan gerak tidak akan terbentuk sendirinya sejalan dengan pertambahan usia. Kita perlu memahami bahwa setiap anak mengalami perjalanan yang berbeda dalam model perkembangan geraknya.

Beberapa penelitian di Indonesia membuktikan bahwa, keterampilan gerak dasar yang seharusnya adalah fondasi awal perkembangan gerak hingga memiliki bakat yang baik masih belum sesuai dengan yang semestinya. Masih banyak guru dan tenaga pendidik yang belum memiliki wawasan, keterampilan dan program dalam pembelajaran gerak dasar bagi anak pada tingkat PAUD/TK dan Sekolah Dasar, Oktarifaldi Dkk (2019). Berdasarkan hal tersebut sebelum mendeteksi bakat anak dan menempatkan pada suatu cabang olahraga yang cocok perlu diberikan pembelajaran gerak yang sesuai dengan kebutuahan mereka.

Untuk mewujudkan hal tersebut lembaga pendidikan seperti TK/PAUD adalah wadah yang tepat dalam merealisasikannya agar dilahirkan anak yang memiliki bakat yang baik. Beberapa kegiatan telah dilakukan pengabdi dan Tim pembelajaran gerak anak usia dini dan telah memberikan manfaat yang berarti. Bakhtiar Dkk (2019) mengatakan "kegiatan ini secara keseluruhan telah memberikan pengetahuan dan pengalaman bagi guru dalam mendemonstrasikan serta merancang pembelajaran gerak dasar anak usia dini kepada mitra (guru-guruPAUD)". Dengan demikian perlu guru dan tenaga pendidik ditingkat PAUD untuk menguasai dan mentransfer pembelajaran gerak hingga anak dapat diarahkan sesuai bakat masing-masing dikemudian hari.

Anak yang terlahir dari keluarga awam akan fungsi dari pentingnya belajar gerak, akan mengalami kesulitan dalam melakukan rangkaian gerakan-gerakan dasar. Sekalipun secara biologis anak tersebut memiliki garis keturunan olahragawan dan sangat berbakat dalam satu cabang olahraga. Jika kemampuan gerak dasar anak tidak dipoles semenjak dini, anak akan mengalami kekakuan dalam merealisasikan gerak. Untuk itu perlu diketahui level kemampuan gerak anak agar perbaikan dapat dilakukan dengan efektif. Oktarifaldi; Syahputra, R; Nur H; Rasyid, W \& Mariati, S (2019) mengatakan, tanpa mengevaluasi dengan mengetahui level gerak anak mustahil kita dapat memberikan solusi atau perbaikan-perbaikanterhadap anak.

Cibiran yang diterima anak atas kemampuan geraknya yang buruk akan membuat anak menjadi kurang percaya diri dan cenderung menutup diri untuk melakukan aktivitas fisik. Hal ini secara tidak langsung telah membunuh bakat luar biasa dari anak tersebut. Karna hanya sekedar untuk melakukan identifikasi bakat olahraga pun anak tersebut tidak mau. Namun, jika seorang anak sudah terbiasa bergerak dan memiliki kemampuan gerak yang baik, anak tersebut akan menjadi percaya diri. Ketika ia diminta untuk melakukan rangkaian gerakan, anak tersebut tidak akan malu-malu dan dengan percaya dirinya anak akan melakukan hal yang diminta.

Kemampuan gerak dasar dan bakat memiliki hubungan linear (Arie; Asnaldi et al., 2019). Bakat sama halnya dengan kemampuan gerak dasar yang harus dipoles semenjak dini. Dalam dunia sains, dikenal dengan golden age atau usia emas anak. Pada usia emas ini, pertumbuhan dan perkembangan gerak anak berada pada fase terbaik. Ketika kita bisa memanfaatkan moment ini, kita dapat menciptakan seorang atlet dengan talenta yang luar bisa. Jadi memang sudah seharusnya identifikasi bakat pada cabang olahraga dilakukan sejak usia yang sangat muda untuk memaksimalkan segala potensi yang dimiliki oleh anak.

Apabila pendeteksian bakat ini dilakukan pada usia remaja, maka akan sulit untuk menempatkan anak pada cabang olahraga yang benar. Dalam menditeksi bakat anak, hal yang terpenting dalam studi awal adalah melihat melihat kemampuan koordinasi yang dimiliki anak. Seseorang yang memiliki kemampuan koordinasi yang baik akan mudah untuk mempelajari berbagai keterampilan gerak, guru diharapkan mampu meningkatkan kemampuan koordinasi anak sekaligus mampu mencarikan metode pembelajaran yang paling tepatuntuk membantu anak yang mermiliki keterampilan koordinasi yang kurang baik, Bakhtiar Dkk (2020). 
Dissemination and Training of Identification and Development of Sport Talent for Physical Education Teachers and Sports Trainers in the Province of West Sumatra

${ }^{1}$ Atradinal, ${ }^{2}$ Risky Syahputra, ${ }^{3}$ Oktarifaldi, ${ }^{4}$ Romi Mardela, ${ }^{5}$ Lucy Ptratama Putri, ${ }^{6}$ Irfan Oktavianus, ${ }^{7}$ Sari Mariati ${ }^{9}$ Zainul Johor, ${ }^{9}$ Syahrial Bakhtiar

Bakat adalah kualitas atau substansi yang dimiliki seseorang atau kelompok, yang membedakan mereka dari orang lain, biasanya mengacu pada satu subjek tunggal. Bakat adalah kemampuan genetik yang terbatas dan diperoleh oleh individu dalam suatu populasi (Pion, 2015). Bakat sangat penting diidentifikasi dari usia dini untuk lebih efektif mengetahui dan mengembangkan potensi mereka dalam dunia olahraga (GelderModel, 2019). Identifikasi bakat dalam olahraga secara tradisional telah dikaitkan dengan olahraga individu yang memiliki persyaratan fisik dan fisiologis yang terpisah, seperti bersepeda, berlari, mendayung, dll. Namun pada saat sekarang ini dengan bantuan perkembangan ilmu pengetahuan dibidang olahraga, para ahli telah menemukan metode baru yang lebih efektif dan efisien dalam menemukan bakat olahraga pada seorang anak. Salah satunya dalah Identifikasi dan Pengembangan Bakat Olahraga (Talent identification and development in Sport) ditemukan oleh Prof. Dr. Johan Pion, Ph.D, Kepala Pusat Departemen Penelitian Identifikasi dan Pengembangan Bakat Olahraga, HAN University of Applied Sciences, Belanda dan Guest Lecturer di Ghent University, Belgia.

Prof. Johan Pion sudah melakukan kerja sama dengan berbagai negara dalam melakukan identifikasi bakat olahraga hingga menghasilkan sampel-sampel yang menjadi juara di Olimpiade. Kerja sama yang sudah dilakukan antara lain dengan Australia, Belanda, Belgia, Kroasia, Singapura, Malaysia dan Indonesia. Hingga saat ini dia masih bekerja sama dengan pemerintah Belgia dan Belanda dalam menjalankan penyeleksian dan pengembangan bakat untuk sampel-sampel olimpiade.

Program identifikasi dan pengembangan bakat olahraga yang dikembangkannya bersama Sportamundi, sebuah organisasi non-profit yang berbasis di Belgia, telah terhubung dengan smartphone melalui aplikasi I Like, I Do, dan I Need. Dengan kemudahan aplikasi ini, tiap tahun dia mengumpulkan data sebesar 20.000 sampel yang dilakukan di Belgia dan Belanda. Talentidentification and development (TID) adalah program yang merupakan bagian dari proses seleksi dan dirancang untuk pengembangan atlet dari usia dini untuk berprestasi di tingkat pertandingan olahraga tertinggi (misalnya, olimpiade dan piala dunia) (K. Johnston, N. Wattie, J. Schorer, and J. Baker, 2018). Biasanya, talent identification (TI) melibatkan secara aktif untuk mengidentifikasi keunggulan tingkat kinerja awal dalam proses pengembangan (K. J. M. Bennett, R. Vaeyens, and J. Fransen, 2019).

Tergabung dalam tim TID Indonesia memberikan pengabdi informasi dan gambaran mengenai pola penjaringan bakat pada tiap-tiap cabang olahraga yang selama ini dilakukan oleh guru PJOK dan maupun pelatih pada masing-masing cabang olahraga di Sumatera Barat. Ternyata selama ini guru PJOK beserta pelatih hanya berpatokan pada hasil kompetisi dalam menjaring bakat-bakat olahraga, metode yang sangat tradisional tanpa memanfaatkan sains dalam bidang keolahragaan. Kurangnya ilmu dan pemahaman yang dialami oleh para guru PJOK dan pelatih inilah yang kemudian memeberikan kontribusi sangat besar terhadap ketidak tercapaian prestasi pada bidang olahraga.

Pelaksanaan kegiatan program pengabdian kepada masyarakat ini dilakukan berdasarkan temuan penelitian terdahulu serta studi dan observasi yang langsung pengabdi lakukan diberbagai kota dan kabupaten di Sumatera Barat. Hasil observasi dan studi awal tersebut, ditemui permasalahan sebagai berikut : (a) Sebagian besar guru-guru PJOK dan pelatih di Sumatera Barat belum memahami bahkan belum mengenal identifikasi bakat. (b) Sebagian besar guru-guru PJOK dan pelatih di Sumatera Barat belum memamahami pentingnya identifikasi bakat sedini mungkin. (c) Guru-guru PJOK dan pelatih di Sumatera Barat belum memiliki keterampilan dalam melakukan identifikasi bakat. (d) Guru-guru PJOK dan pelatih di Sumatera Barat belum mengetahui alat ukur dan instrument tes yang digunakan untuk mengetahui bakat anak serta cara mengevaluasinya.

Berdasarkan kondisi serta situasi tersebut, untuk mengejar ketertinggalan bagi guru-guru PJOK dan pelatih yang telah berada di lapangan khususnya di sekolah tempat tugas masing-masing pengabdi telah mengadakan suatu sosialisasi tentang pemahaman tentang materi identifikasi bakat serta cara mengimplementasikan dalam pengajaran kepada peserta didik dan didik latih. Setelah memahami dan memiliki wawasan kegiatan selanjutnya pengabdi akan melanjutkan dengan bimbingan dalam mengevaluasi bakat anak.

Dalam kegiatan pelatihan ini, setelah di observasi dan di telaah tim TID bersama pengabdi ditemukan permasalahan yang mesti dicarikan solusi agar kendala dapat dipecahkan. Situasi yang ada pada khalayak mitra ini harus diberikan solusi yang pengabdi wujudkan melalui pelatihan yang dilakukan kepada guru-guru PJOK dan pelatih di Sumatera Barat. Fokus kegiatan adalah melatih 


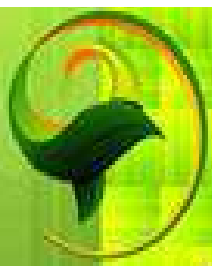

Journal Humanities: Jurnal Pengabdian kepada Masyarakat

Volume 1, Nomor 1, Bulan Juni, 2020.

E - ISSN 2715-5471

Doi: https://doi.org/10.24036/jha.0102.2019.04

guru untuk :(a) Memiliki wawasan dan pemahaman tentang pentingnya identifikasi bakat pada anak, (b) mengetahui dan memiliki kemampuan merealisasikan instrument tes identifikasi bakat, (c) terampil dalam menggunakan instrument Identifikasi bakat, (d) mengetahui dan mampu mengukur keberbakatan anak usia dini di tempat tugas masing-masing.

\section{SOLUSI DAN TARGET}

Pengabdi menawarkan program yang bisa digunakan oleh guru PJOK beserta pelatih dalam rangka mengatasi permasalah yang terjadi didaerah masing-masing, yaitu panduan penggunaan aplikasi online I Like dan I Do sebagai bagian dari program identikasi bakat. Sangat diharapkan kedua aplikasi dapat membantu guru PJOK dan pelatih dalam menjaring talent-talenta luar biasa pada setiap cabang olahraga. I do mengarah pada aktivitas atau bentuk tes fisik yang terdiri dari 14 item tes yang mengandung unsur kelincahan, kekuatan, keseimbangan, koordinasi, daya tahan, tinggi dan berat badan anak. Sedangkan pada aplikasi I like, terdapat setidaknya 18 item pertanyaan yang disertai gambar terhadap aktivitas fisik apa saja yang paling digemari oleh anak. Ada berlari, melompat, memanjat, memukul bola, menendang bola, meniti balok keseimbangan, apakah anak lebih menyukai bermain dalam kelompok atau tidak, apakah anak lebih suka bermain di luar ruangan atau di dalam ruangan dan masih banyak lagi pertanyaan seputar aktivitas fisik favorit anak.

Pengabdi juga sangat mengharapkan agar guru PJOK dan pelatih benar-benar bisa memahami setiap item dari instrument yang ada. Kedepannya pengabdi juga berharap dapat mengambangkan aplikasi yang didapatka dari Sportamundi menjadi satu bentuk buku panduan atau buku saku yang dapat digunakan oleh oleh semua guru PJOK dan pelatih cabang olahraga, baik cabang yang potensial maupun kurang potensial. Dengan adanya pelatihan bagaimana cara menggunakan aplikasi online I Like dan I Do ini, sangat besar harapan pengabdi agar kedepanya guru PJOK dan pelatih dapat merasa lebih percaya diri dalam melakukan identifikasi serta pengambangan bakat, karena telah didukung dengan ilmu pengetahun, teknologi serta sarana dan prasarana. Oleh sebab itu, identifikasi dan pengambangan bakat pada anak sedini mungkin dapat memberikan dampak positif bagi peningkatan prestasi olahraga Indoneisia dimasa mendatang.

Beberapa hal yang dirasa patut untuk guru PJOK dan pelatih perhatikan selama pelatihan identifikasi bakat olahraga serta cara menggunakan instrument I like dan I do adalah sebagai berikut;

1. Memahami benar apa itu bakat dan tatalaksana pengidentifikasian bakat pada cabang olahraga. Maksudnya, guru PJOK dan pelatih benar-benar diharapkan memahami seputar bakat pada anak serta bagaimana prosedur agar anak dapat ditempatkan pada cabang olahraga yang benar pada usia sekolah awal.

2. Pembuatan buku panduan yang nantinya dapat digunakan oleh guru PJOK dan pelatih tentang pedomana identifikasi dan pengambangan bakat pada cabang olahraga pada usia sekolah awal.

3. Produk akhir dapat dinilai oleh ahli yang bersangkutan, seperti ahli pertumbuhan dan perkembangan fisik serta motorik, belajar motorik, ahli gerak dasar dan ahli identifikasi dan pengembangan bakat anak pada masa sekolah awal.

4. Guru PJOK dan pelatih dijadikan sebagai barisan terdepan dalam peyampaian informasi kepada siswa maupun anak latih serta masyarakat awam yang belum paham betul dengan pentingnya identifikasi bakat pada masa sekolah awal dengan cara yang tepat dan benar.

\section{METODE PELAKSANAAN}

Pelaksanaan kegiatan pengabdian ini setidaknya dapat meningkatkan pengetahuan, dan keterampilan guru PJOK dan Pelatih Olahraga dalam peningkatan penguasaan keterampilan gerak dasar dan mengidentifikasi bakat olahraga yang akan ditransfer kepada anak di sekolah-sekolah dan klub tempat tugas. Fokus kegiatan pengabdian ini adalah dalam melatih guru untuk mengenal gerak dasar dan mempraktekkan instrument identifikasi bakat olahraga anak usia dini, mempraktakkan cara mengukur dan menggunakan instrument test identifikasi bakat olahraga seperti aplikasi I like dan I do. Kegiatan penting yang harus dilakukan secara kontiniu adalah membangun komunikasi yang baik 
Dissemination and Training of Identification and Development of Sport Talent for Physical Education Teachers and Sports Trainers in the Province of West Sumatra

${ }^{1}$ Atradinal, ${ }^{2}$ Risky Syahputra, ${ }^{3}$ Oktarifaldi, ${ }^{4}$ Romi Mardela, ${ }^{5}$ Lucy Ptratama Putri, ${ }^{6}$ Irfan Oktavianus, ${ }^{7}$ Sari Mariati ${ }^{9}$ Zainul Johor, ${ }^{9}$ Syahrial Bakhtiar

antara lembaga Universitas Negeri Padang (pengabdi) dan Mitra (guru PJOK dan pelatih Olahraga Sumatera Barat ) setelah kegiatan dilaksanakan. Hal ini bertujuan agar kegiatan yang dilakukan tidak terputus dan akan terus berlanjut baik berupa diskusi, informasi hingga transfer ilmu dan temuan baru yang penulis dapatkan melalui riset berikutnya dengan kajian yang terkait. Tahap kegiatan pengabdian sebagai berikut :

1. Observasi dan sosialisasi ke daerah mitra (sekolah-sekolah dan klub olahraga yang terpilih)

2. Melakukan wawancara tentang materi pengabdian yang akan disampaikan

3. Membarikan beberapa pertanyaan menggunakan motode wawancara secara random ke beberapa guru di beberapa sekolah dan klub olahraga

4. Menyebarkan angket yang berisi pertanyaan, pendapat dan pengalaman guru PJOK dan pelatih olahraga terkait materi yang berjumlah 80 rangkap secara random melalui dinas pendidikan kota dan kabupaten di Sumatera Barat.

5. Mengumpulkan kembali angket yang telah diisi oleh perwakilan guru PJOK dan pelatih olahraga di kota dan kabupaten di Sumatera Barat

6. Mengenalkan beberapa pengetahuan penting tentang pertumbuhan dan perkembangan anak, gerak dasar serta bentuk pengembangan gerak dasar terhadap anak usia dini

7. Melakukan simulasi dengan mempraktekkan Instrumen aplikasi I Like dan I Do terhadap anak di beberapa SD dan klub olahraga di kota dan kabupaten di Sumatera Barat.

8. Melakukan pendampingan implementasi Instrumen I Like dan I DO setelah kegiatan dilaksanakan dengan metode diskusi dan pemecahan masalah di daerah mitra dan tempat tugas masing-masing di kota dan kabupaten di Sumatera Barat

\section{PELAKSANAAN KEGIATAN}

Sebelum kegiatan pengabdian dilaksanakan, tim pengabdian melakukan proses observasiterlebih dahulu kepadakhalayak sasaran, guna menemukan masalah yang ada pada mitra, selanjutnya pengabdi melakukan sosialisasi dengan melakukan diskusi kebeberapa sekolah menemui guru PJOK, kepala sekolah dan pengurus serta pelatih olahraga di kota dan kabupaten Sumatera Barat untuk berkomunikasi dan menjelaskan tujuan dan pentingnya kegiatan pengabdian ini dilaksanakan. Kegiatan pengabdian ini dilakukan melalui:

\section{Pemberian Materi}

Pemberian materi dilakukan melalui beberapa metode kepada khalayak sasaran tentang identifikasi bakat serta instrument evaluasi identifikasi bakat dan penggunaannya. Materi yang diberikan memuat informasi tentang :(a) Wawasan pentingnya identifikasi bakat bagi anak usia dini, (b) Pengetahuan dan keterampilan identifikasi bakat bagi guru PJOK dan pelatih, (c) Instrument dan pengukuran Bakat Olahraga, (d) Keterampilan dalam mengaplikasikan instrument identifikasi bakat anak. Metode tersebut adalah: metode ceramah, demonstrasi, diskusi serta pemecahan masalah, selanjutnya pengabdi melakukan pendampingan dalam realisasi materi setelah kegiatan pelatihan dilakukan.

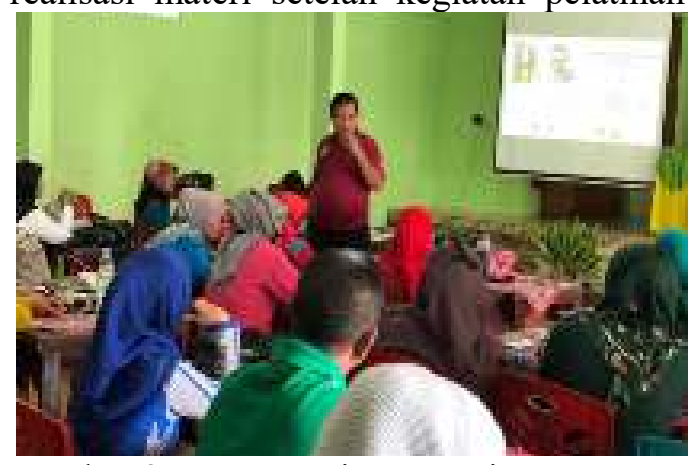

Gambar 2. Penyampaian Materi

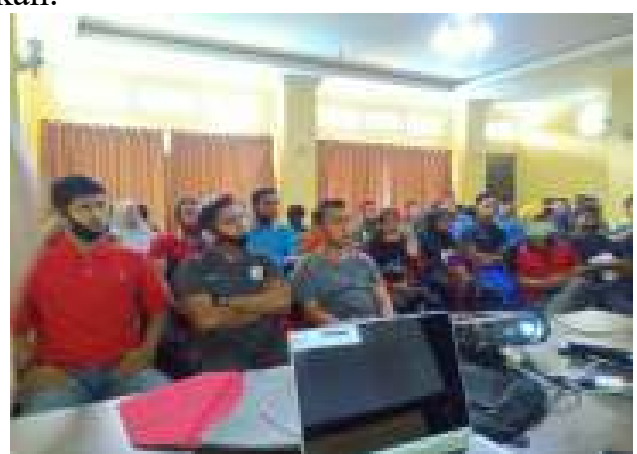

Gambar 3. Penyampaian Materi

\section{Melakukan Diskusi Tentang Materi Identifikasi Bakat}

Diskusi ini dilakukan agar khalayak sasaran lebih memahami tentang identifikasi bakat.

Khalayak sasaran sangat antusias dalam kegiatan diskusi ini karena mereka memiliki rasa ingin 


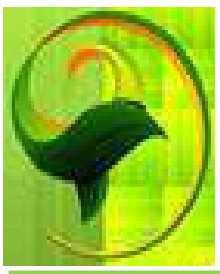

Journal Humanities: Jurnal Pengabdian kepada Masyarakat

Volume 1, Nomor 1, Bulan Juni, 2020.

E - ISSN 2715-5471

Doi: https://doi.org/10.24036/jha.0102.2019.04

tahu yang besar tentang pentingnya identifikasi bakat bagi anak usia dini dan cara mengevaluasi awal kemampuan anak di Sekolah Dasar.

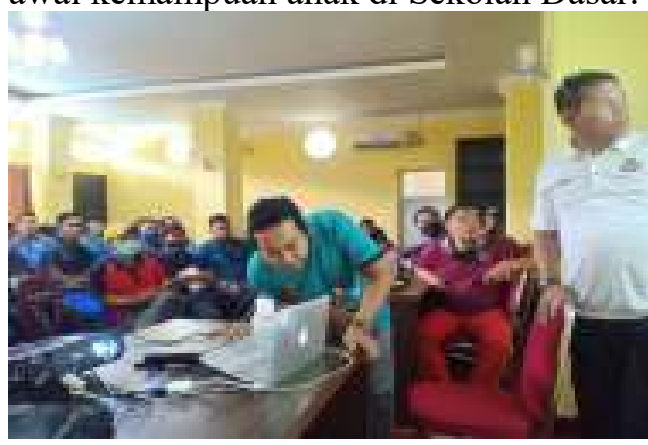

Gambar 4. Diskusi tentang Identifikasi Bakat

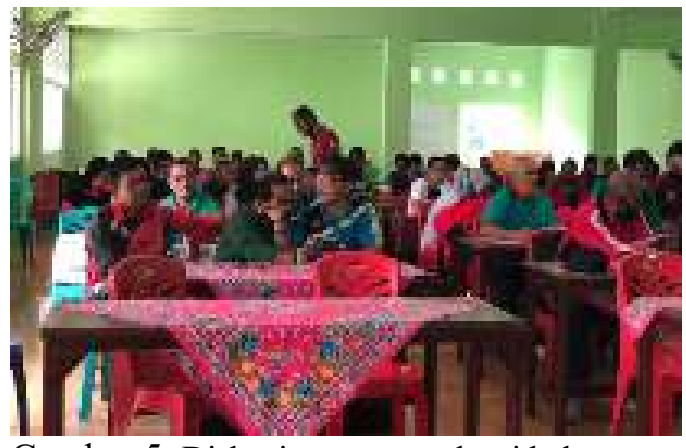

Gambar 5. Diskusi tentang evaluasi bakat

3. Melakukan Praktek Identifikasi Bakat (I do dan I Like)

Setelah meteri disampaikan dan dilanjutkan dengan diskusi berkenaan dengan substansi, sesi selanjutnya dilakukan praktek I do dan I Like bagi masing-masing guru dan pelatih agar transfer pengetahuan benar-benar diserap dan dikuasai dengan baik. Selanjutnya praktek ini bertujuan untuk mendalami dan mengetahui secara ril proses identifikasi bakat dan proses evaluasi yang akan direalisasikan guru terhadap anak di sekolah dan di klub. Dalam melakukan identifikasi bakat melalui I do dan I Like haruslah dimulai dengan item yang paling mudah, sesuai dan selaras dengan tujuan yang akan dicapai.

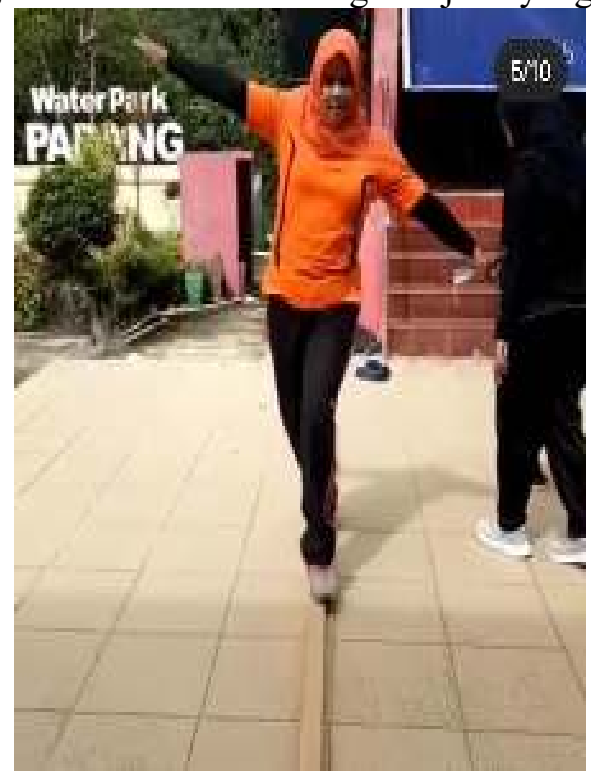

Gambar 6. Praktek item I do

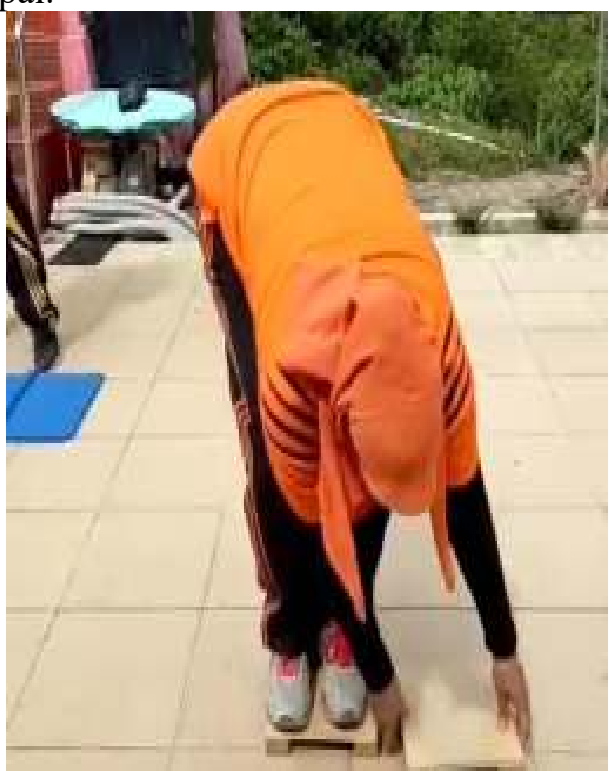

Gambar 7. Praktek item I do 
Dissemination and Training of Identification and Development of Sport Talent for Physical Education Teachers and Sports Trainers in the Province of West Sumatra

${ }^{1}$ Atradinal, ${ }^{2}$ Risky Syahputra, ${ }^{3}$ Oktarifaldi, ${ }^{4}$ Romi Mardela, ${ }^{5}$ Lucy Ptratama Putri, ${ }^{6}$ Irfan Oktavianus, ${ }^{7}$ Sari Mariati ${ }^{9}$ Zainul Johor, ${ }^{9}$ Syahrial Bakhtiar

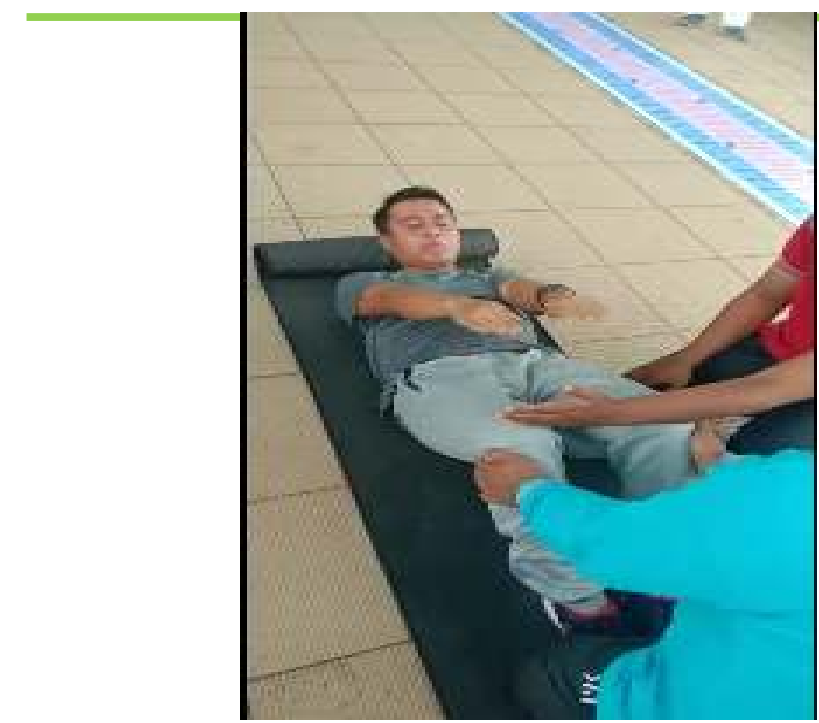

Gambar 8. Praktek item I do

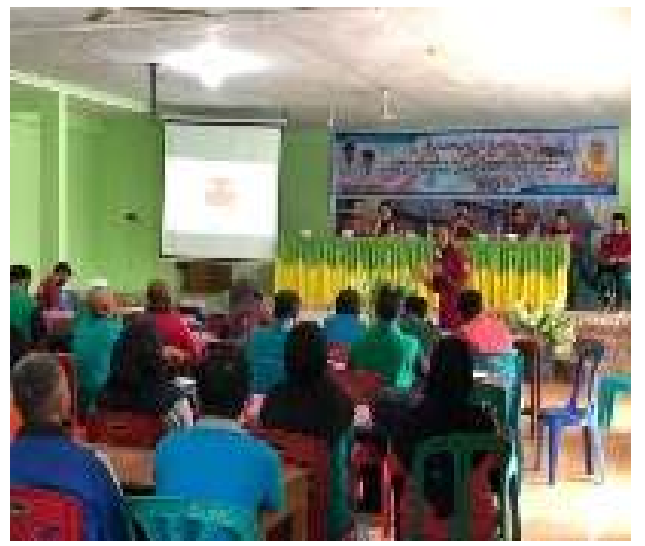

Gambar 10. Penjelasan item I like

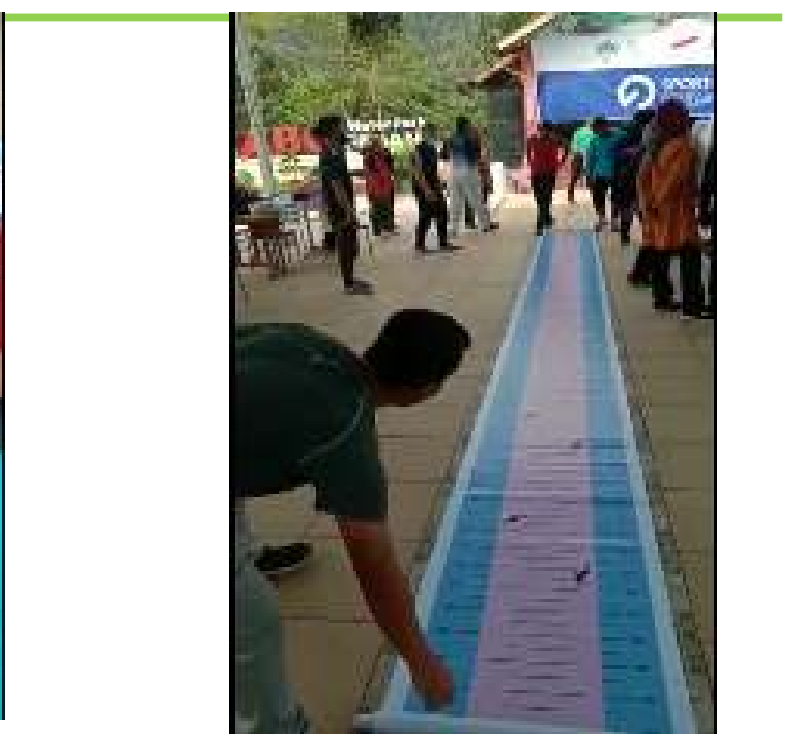

Gambar 9. Praktek item I do

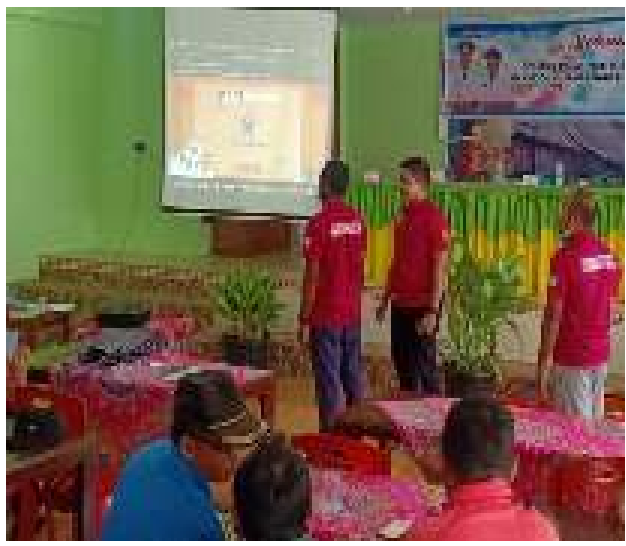

Gambar 11. Penjelasan item I like

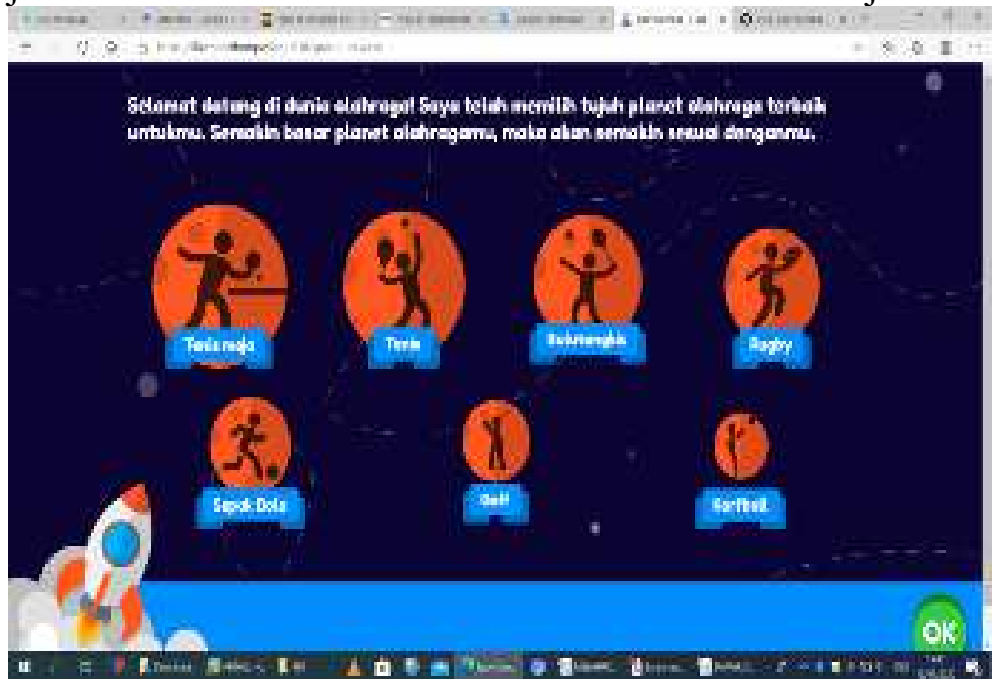

Gambar 12. Tampilan I Like setelah mendapatkan cabang olahraga yang tepat bagi anak

4. Melakukan Pendampingan Dalam Implementasi Pembelajaran dan Aplikasi instrument Di Sekolah dan Klub

Pengabdian melakukan kegiatan pendampingan kepada Mitra (peserta Pelatihan) dengan mengunjungi mitra 2 kali pertemuan. Kegiatan yang dilakukan adalah berupa diskusi, konsultasi serta evaluasi dalam proses implementasi instrument TID di sekolah dan klub. Kegiatan ini 
Journal Humanities: Jurnal Pengabdian kepada Masyarakat

Doi: https://doi.org/10.24036/jha.0102.2019.04

merupakan inti dari tujuan kegiatan yang mana pengabdi memberikan pengetahuan baru yang teraplikasi oleh pelatih dan guru PJOK di tempat tugas masing-masing.

\section{HASIL DAN PEMBAHASAN}

Setelah terselesaikanya kegiatan pelatihan ini, langkah selanjutnya yang pengabdi lakukan adalah melakukan monitoring dan pendampingan dalam pengimplementasian materi yang telah diberikan. Monitoring dan pendampingan ini pengabdi lakukan agar kedepanya tidak terjadi kesalahan dalam penggunaan aplikasi I like dan I do. Kesalahan-kesalahan kecil yang terjadi di lapangan bisa saja akan menjadi masalah besar dikemudian hari serta ketidak tercapaain tujuan dari pengimplementasian aplikasi ini. Berdasarkan evaluasi kegiatan yang diikuti 52 orang guru dan pelatih olahraga dari kota dan kabupaten di Sumatera Barat, maka dapat ditampilkan hasil dari capaian kegiatan yang telah dilakukan.

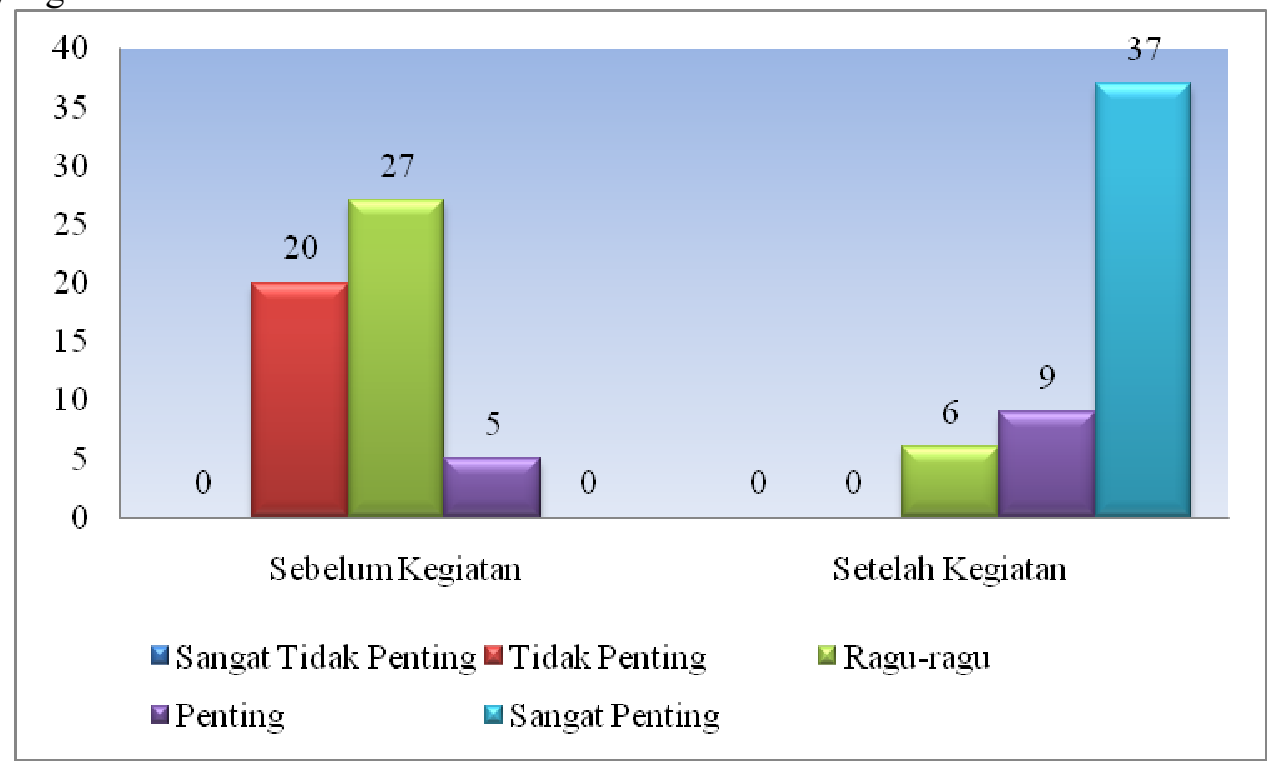

Gambar 13. Grafik peningkatan pengetahun guru PJOK dan Pelatih cabang olahraga terhadap pentingnya mengetahui identifikasi dan pengmabngan bakat olahraga

Dalam pelaksanaan kegiatan terlihat awal kegiatan ini pengabdi menyebarkan pre tes tentang pentingnya pelaksanan kegiatan identifikasi dan pengembangan bakat olahraga terhadap 52 orang responden yang sekaligus sebagai peserta kegiatan. Terlihat hamper $80 \%$ responden menanggapi dengan tidak penting atau tagu-ragu, setelah kegiatan dilaksanakan dan beberapa testimony tingkat keberhasilan di Negara lain responden memberikan tanggapan positif terhadap kegiatan ini. Dengan demikian dapat diartikan kegiatan yang pengabdi lakukan adalah hal yang cukup penting dan perlu disebarluaskan di Indonesia. Hal ini harus dimulai dari lingkungan formal sedini mungkin seperti PAUD dan Sekolah Dasarhingga klub olahraga, yang menjadikan guru dan pelatih sebagai ujung tombak penyebaran informasi dan praktisi yang aktif dalam pengembangan bakat olahraga.

Kegiatan ini tidak hanya selesai pada pelatihan dan sosialisasi saja, Instruktur dan Tim TID Indonesia bersedia secara kooperatif dan aktif membimbing guru dan pelatih dalam menjalankan program TID dengan bersinergi bersama di Sumatera Barat. Pendampingan serta monitoring pengabdi lakukan satu minggu pasca kegiatan pengabdian yang pengabdi lakukan, yaitu pada bulan Juni 2020 . Monitoring dan pendampingan ini pengabdi lakukan untuk melihat sejauh mana kemampuan yang dimiliki oleh mitra dalam mengimplementasiakn ilmu yang telah didapatkan selama pelatihan. Hal ini juga dilakukan demi memecahkan permasalahan-permasalahan yang dialami oleh mitra di lapangan. Pada minggu pertama bulan Juli 2020 pengabdi kembali melakukan monitoring dan pendampingan. Hal ini berfokus pada diskusi dan memperbaiki kesalah-kesalahan yang masih dilakukan oleh gur PJOK dan pelatih selama menggunakan aplikasi I do dan I like. Kemudian pengabdi dan mitra juga mendiskusikan beberapa hal yang mungkin dirasa perlu demi keberhasilan program ini dimasa mendatang. Dengan suksesnya kegiatan ini diyakini bakat anak-anak di Sumatera Barat akan semakin 
Dissemination and Training of Identification and Development of Sport Talent for Physical Education Teachers and Sports Trainers in the Province of West Sumatra

${ }^{1}$ Atradinal, ${ }^{2}$ Risky Syahputra, ${ }^{3}$ Oktarifaldi, ${ }^{4}$ Romi Mardela, ${ }^{5}$ Lucy Ptratama Putri, ${ }^{6}$ Irfan Oktavianus, ${ }^{7}$ Sari Mariati ${ }^{9}$ Zainul Johor, ${ }^{9}$ Syahrial Bakhtiar

menjamur serta banyak cabang olahraga yang akan membuahkan prestasi yang gemilang, mulai dari tingkat pelajar, daerah, wilayah hingga nasional.

\section{DISKUSI}

Prof. Johan Pion sudah melakukan kerja sama dengan berbagai negara dalam melakukan identifikasi bakat olahraga hingga menghasilkan sampel-sampel yang menjadi juara di Olimpiade. Kerja sama yang sudah dilakukan antara lain dengan Australia, Belanda, Belgia, Kroasia, Singapura, Malaysia dan Indonesia. Hingga saat ini dia masih bekerja sama dengan pemerintah Belgia dan Belanda dalam menjalankan penyeleksian dan pengembangan bakat untuk sampel-sampel olimpiade. Program identifikasi dan pengembangan bakat olahraga yang dikembangkannya bersama Sportamundi, sebuah organisasi non-profit yang berbasis di Belgia, telah terhubung dengan smartphone melalui aplikasi I Like, I Do, dan I Need. Dengan kemudahan aplikasi ini, tiap tahun dia mengumpulkan data sebesar 20.000 sampel yang dilakukan di Belgia dan Belanda.

\section{KESIMPULAN}

Berdasarkan kegiatan Pengabdian Kepada Masyarakat yang sudah dilaksanakan di kota Padang, dapat disimpulkan sebagai berikut:

1. Pelaksanaan Kegiatan Pengabdian Kepada Masyarakat ini telah berhasil dilaksanakan dengan baik tanpa mengalami kendala yang berarti.

2. Kegiatan Kegiatan Pengabdian Kepada Masyarakat ini memberikan edukasi bermanfaat kepada masyarakat (guru, orang tua, peserta didik) di Sumatera Barat mengenai defenisi, pemahaman dan wawasan mengenai identifikasi bakat dan penggunaan instrument I do dan I like bagi guru-guru PJOK dan pelatih di Sumatera Barat

3. Kegiatan Pengabdian Kepada Masyarakat ini memberikan gambaran dan fakta yang terjadi secara umum mengenai bakat anak serta pentingnya identifikasi bakat pada anak sedini mungkin.

4. Kegiatan ini secara keseluruhan telah memberikan pengetahuan dan pengalaman bagi guru dan pelatih dalam mendemonstrasikan serta pengimplementasian instrument identifikasi bakat anak kepada mitra (guru-guru PJOK dan pelatih). Selanjutnya guru PJOK dan pelatih di Sumatera Barat telah memiliki pengalaman dan keterampilan dalam mengevaluasi bakat anak, yang mana mereka juga di wajibkan menyebarluaskan kepada teman sejawat di daerah masingmasing.

\section{PENGAKUAN}

Ucapan terimakasih yang tak terhingga kepada pemerintah daerah kota dan kabupaten di Sumatera Barat melalui Dinas Pendidikan dan Kebudayaan yang telah memfasilitasi pengabdi dalam melakukan kegiatan ini. Ucapan terimakasih kepada tim pembelajaran gerak dasar, Tim TID Indonesia melalui yayasan Sekolah Olahraga (SEKORA) dan rekan-rekan dosen serta teman sejawat yang telah memberikan dukungan dan bantuan moril hingga pengabdian ini selesai dilaksanakan. Selanjutnya ucapan terima kasih kepada mitra kerja dan penggagas Talent Identifikasi Bakat di Belgia dan Belanda yang telah memberikan pengetahuan dan ilmu yang baru hingga dapat di sosialisasijan di Sumatera Barat dan Indonesia.

\section{DAFTAR PUSTAKA}

Asnaldi, Arie;, Bakhtiar, S. Z., \& Wenly, A. P. (2019). Explosion of limb mus cles on the ability of Mae Geri Chudan Karateka Lemkari. Jurnal Performa.

http://performa.ppj.unp.ac.id/index.php/kepel/article/view/89

Asnaldi, Arie, Yelis, R., Zulman, Atradinal, Putri, L. P., \& Bakhtiar, S. (2020). The Differences of Ability in the Level of Development on Control Objects of Early Childhood Education Students in Pariaman City and Padang Panjang City. Proceedings of the 1st International Conference of Physical Education (ICPE 2019), 97-100. https://doi.org/10.2991/assehr.k.200805.028

Pion, J. (2015). Johan Pion. The Flemish Sports Compass From Sports Orientation to Elite Performance Prediction, 1-235. 
Journal Humanities: Jurnal Pengabdian kepada Masyarakat Volume 1, Nomor 1, Bulan Juni, 2020. E - ISSN 2715-5471

Doi: https://doi.org/10.24036/jha.0102.2019.04

Andrews, L. M., Hesselink, D. A., van Schaik, R. H. N., van Gelder, T., de Fijter, J. W., Lloberas, N., ... \& de Winter, B. C. M. (2019). A population pharmacokinetic model to predict the individual starting dose of tacrolimus in adult renal transplant recipients. British journal of clinical pharmacology, 85(3), 601-615.

Bakhtiar, S., Khairuddin, K., \& Yelis, R. (2020). PENGARUH UMPAN BALIK, KOORDINASI TERHADAP KEMAMPUAN OBJEK KONTROL SISWA PAUD KOTA PADANG PANJANG. Sporta Saintika, 5(1), 59-72.

Bakhtiar, S., Oktarifaldi, O., \& Putri, L. P. (2019). Implementation of Learning and Fundamental Motor Skill Measurement of Early Childhood Motor Skill for PAUD Teachers in Padang Panjang City. Jurnal Humanities Pengabdian Kepada Masyarakat, 1(1), 36-47.

Gonçalves, C. E., Rama, L. M., \& Figueiredo, A. B. (2012). Talent identification and specialization in sport: an overview of some unanswered questions. International journal of sports physiology and performance, 7(4), 390-393.

Goodway, J. D., \& Robinson, L. E. (2006). SKIPing toward an active start: Promoting physical activity in preschoolers. Beyond the Journal: Young Children, 61(3), 1-6.

Hands, B. P. (2012). How fundamental are fundamental movement skills?. Active and Healthy Magazine, 19(1).

Johnston, K., Wattie, N., Schorer, J., \& Baker, J. (2018). Talent identification in sport: a systematic review. Sports Medicine, 48(1), 97-109.

Oktarifaldi, O., Syahputra, R., \& Putri, L. P. (2019). The Effect Of Agility, Coordination and Balance On The Locomotor Ability Of Students Aged 7 To 10 Years. Jurnal Menssana, 4(2), 190-200.

Pang, A. W. Y., \& Fong, D. T. P. (2009). Fundamental motor skill proficiency of Hong Kong children aged 6-9 years. Research in Sports Medicine, 17(3), 125-144.

Payne, V. G., \& Isaacs, L. D. (2017). Human motor development: A lifespan approach. Routledge.

Pion, J. (2015). The Flemish sports compass: From sports orientation to elite performance prediction (Doctoral dissertation, Ghent University).

Syahputra, R., Nur, H., Rasyid, W., \& Mariati, S. (2019). Implementation of Basic Motion Learning and Use of Test Instrument of Gross Motor Development (TGMD) in Evaluating Basic Motion Skills. Jurnal Humanities Pengabdian Kepada Masyarakat, 1(1), 1-9. 